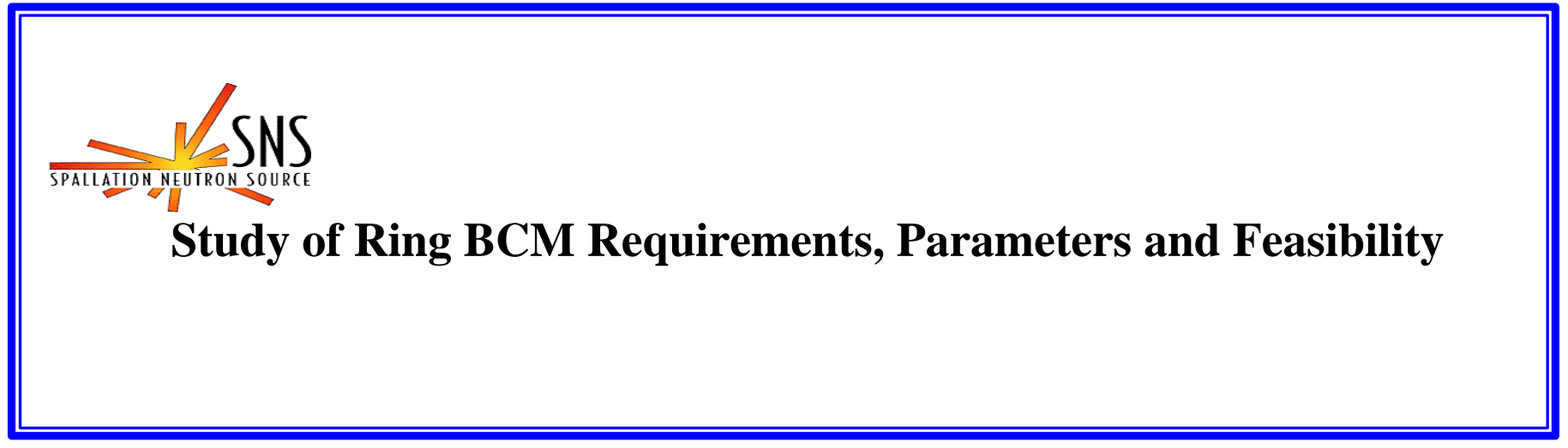

BNL/SNS TECHNICAL NOTE

NO. 062

M. Kesselman

May 20, 1999

ALTERNATING GRADIENT SYNCHROTRON DEPARTMENT BROOKHAVEN NATIONAL LABORATORY UPTON, NEW YORK 11973 


\title{
Study of Ring BCM Requirements, Parameters, and Feasibility
}

\author{
M. Kesselman - May 20, 1999
}

\section{Summary}

The requirements for beam current monitors for the HEBT, RING, and RTBT lines are established. Results of testing using reduced capacitance winding techniques, and load resistance matching, indicate the possibility of producing a low droop current transformer $(<0.1 \% / \mathrm{ms})$ with a rise time near 50ns. Measurements made on a smaller core are not easily scalable, requiring additional tests on cores sized appropriately for the SNS Ring. A compromise between droop, rise time and transient response may be necessary.

\section{General Requirements}

Beam Current Monitors (BCM) provide information about the current or charge in the SNS. There are monitors located in the High Energy Beam Transport line (HEBT), the Ring accumulator (RING), and Ring to Target Beam Transport line (RTBT). The HEBT beam comes from the $1.0 \mathrm{GeV} \mathrm{H}$-minus linear accelerator (LINAC), and is approximately one millisecond long, with a peak current of $56 \mathrm{~mA}$. The beam has an $805-\mathrm{MHz}$ microstructure and is chopped to lengths of 546 nanoseconds with $295 \mathrm{~ns}$ gaps forming a mini-structure. These pulses repeat for one millisecond at sixty times per second forming a macrostructure. The RING accumulates the 546ns pulses and, therefore, has an increasing pulse current. This current can rise to as much as 100 A peak, depending upon the bunch shape. The RTBT line accepts this full beam at a sixty $\mathrm{Hz}$ rate.

With high peak currents expected in the RING and RTBT lines one must assure that the current time integral does not saturate the core. For a constant current input Strauss (Ref. 1) shows that;

$$
\mathrm{t}_{\mathrm{s}}=\sigma l \mathrm{~B}_{\mathrm{s}} \mathrm{d}^{2} / 4 \mathrm{~N}\left(\mathrm{I}_{\mathrm{a}}-\mathrm{I}_{\mathrm{c}}\right)
$$

Where: $\sigma=$ volume conductivity of the core

$$
\begin{aligned}
& l=\text { mean magnetic path length } \\
& \mathrm{B}_{\mathrm{s}}=\text { Saturation Flux Density } \\
& \mathrm{d}=\text { core thickness } \\
& \mathrm{N}=\text { number of primary turns } \\
& \mathrm{I}_{\mathrm{a}}=\text { applied current } \\
& \mathrm{I}_{\mathrm{c}}=\text { current to overcome the coercive force }
\end{aligned}
$$


From the above we obtain an $I^{*} t$ product of 166 for a mean core length of 10.5 inches and 1 turn $\left(B_{s}=8000\right.$ Gauss, $\rho=65 \times 10^{-6} \mathrm{Ohm} \mathrm{cm}, \mathrm{d}=1 \mathrm{inch}$ ). This provides a wide margin for the SNS Ring and transfer line transformers.

To analyze the RTBT line Fast Current Transformers (FCT) will be used to provide bunch shape and total charge information. The HEBT will use both FCTs and low droop BCMs to examine bunch characteristics as well as over-all current and charge. Bunch characteristics are available from the FCT, while the BCM can provide macro-pulse current information. Both can provide charge information by integration of the current. The RING will have both a FCT and BCM and may include a special Beam-In-Gap (BIG) monitor. The following table (Table 1) shows the beam current monitor requirements.

Table 1 - Beam Current Monitor Requirements

\begin{tabular}{|c|c|c|c|}
\hline & HEBT & RING & RTBT \\
\hline FCT & $1+1^{*}$ & 1 & 5 \\
\hline BCM & $3+1^{*}$ & 1 & 0 \\
\hline BIG & 0 & 1 & 0 \\
\hline
\end{tabular}

* Supplied by LANL

3.0 Goals and expected achievable parameters

\subsection{FCT}

A commercially available FCT will be used to capture the fast changing characteristics of the beam. One such transformer made by Bergoz Instruments (see appendix) will provide a rise time of about one nanosecond, and a droop of $0.1 \%$ per microsecond. Electronics to condition the signals from this transformer will provide wide bandwidth buffering and gain control in the Ring. Different electronics may be necessary to provide adequate gain for the HEBT line, and to accommodate the currents encountered in both the RING and RTBT lines. Variable gain will be required in the RING, with two gains required in the RTBT (one for single-turn intensity operation, the other for normal operation).

These requirements established the following bandwidth requirements:

FCT:

$\mathrm{Fmax}=350 \mathrm{MHz}$

Fmin $=159 \mathrm{~Hz}$

Tau $=0.999 \mathrm{sec}($ The L/R droop time constant $)$

\section{$3.2 \mathrm{BCM}$}

A specification was established to provide a BCM for the ring that could follow the ministructure and provide low droop for the entire duration of the macrostructure pulse. This will minimize baseline undershoot and simplify signal conditioning. 
Rise time response: capable of following a 50ns rise time

Droop requirement: capable of holding droop to $0.1 \%$ for 1 millisecond

These requirements established the following bandwidth requirements:

BCM:

Fmax $=7 \mathrm{MHz}$

$\mathrm{Fmin}=0.159 \mathrm{~Hz}$

$\mathrm{Tau}=0.999 \mathrm{Sec}$

\subsection{BIG}

The BIG monitor has very stringent requirements. Transient settling time is a major concern due to the need to see a small beam $(<0.01 \%$ of peak) in the gap after the main pulse goes by. At this time it is not clear that such a device can be provided.

This requires settling to $0.1 \%$ within $75 \mathrm{nS}$ to $100 \mathrm{nS}$.

Rise time response: capable of following a $50 \mathrm{nS}$ rise time

Droop requirement: capable of holding droop to $0.1 \%$ for 1 millisecond

These requirements established the following bandwidth requirements:

BIG:

Fmax $=12 \mathrm{MHz}$ to $17 \mathrm{MHz}$

$\mathrm{Fmin}=0.159 \mathrm{~Hz}$

$\mathrm{Tau}=0.999 \mathrm{Sec}$

Table 2 shows the goals and expected achievable parameters.

Table 2 - Current Monitor Parameters

\begin{tabular}{|c|c|c|c|}
\hline & FCT & BCM & BIG \\
\hline Goals & & & $20 \mathrm{~ns}$ to 30ns \\
\hline Rise Time & $1 \mathrm{~ns}$ & $50 \mathrm{~ns}$ & $0.1 \% / \mathrm{ms}$ \\
\hline Droop & $0.1 \% / \mathrm{us}$ & $0.1 \% / \mathrm{ms}$ & $75 \mathrm{~ns}-100 \mathrm{~ns}$ \\
\hline $\begin{array}{c}\text { Settling Time } \\
(0.1 \%)\end{array}$ & - & - & \\
\hline $\begin{array}{c}\text { Achievable } \\
\text { Parameters }\end{array}$ & & & unknown \\
\hline Rise Time & $1 \mathrm{~ns}$ & $50 \mathrm{~ns}$ to $70 \mathrm{~ns}$ & unknown \\
\hline Droop & $0.1 \% / \mathrm{us}$ & $0.1 \%$ to $0.2 \% / \mathrm{ms}$ & unknown \\
\hline Settling Time & - & - & \\
\hline
\end{tabular}




\section{Basic Current Transformer Scaling Concepts}

The equivalent circuit of a wide band current transformer is complex. It not only is non-linear due to the magnet core characteristics, but at high frequencies could involve transmission line analysis and complex electromagnetics.

Some basic concepts related to the design of toroidal current transformers helps to determine scaling requirements.
A- $\quad \operatorname{Droop}\left(t_{d}\right)$
$t_{d} \alpha \mathrm{L} / \mathrm{R}$
or $\quad \mathrm{t}_{\mathrm{d}} \alpha \mu \mathrm{N}^{2} \mathrm{~A} / l \mathrm{R}$
B- Rise Time $\left(t_{r}\right)$
$\mathrm{t}_{\mathrm{r}} \alpha \mathrm{RC}_{\mathrm{S}} \quad$ or $\quad \mathrm{t}_{\mathrm{r}} \alpha \sqrt{\mathrm{L}_{\mathrm{e}} \mathrm{C}_{\mathrm{S}}}$
but;
$\mathrm{L}_{\mathrm{e}} \alpha \mathrm{N}^{2} \quad$ and $\quad \mathrm{C}_{\mathrm{S}} \alpha \mathrm{N}$
Therefore;
$t_{r} \alpha \mathrm{NR} \quad$ or $\quad \mathrm{t}_{\mathrm{r}} \alpha \mathrm{N}^{3 / 2}$

\section{C- $\quad$ Signal Output (Vo )}
Vo $\alpha R_{L} / \mathrm{N}$

Where:

$$
\begin{aligned}
& \mathrm{L}=\text { low frequency inductance } \\
& \mathrm{L}_{\mathrm{e}}=\text { leakage inductance } \\
& \mathrm{C}_{\mathrm{S}}=\text { stray coil capacitance } \\
& \mathrm{R}=\text { total series resistance of secondary }\left(\mathrm{R}_{\mathrm{L}}+\mathrm{R}_{\mathrm{W}}\right) \\
& \mathrm{R}_{\mathrm{L}}=\text { load resistance } \\
& \mathrm{R}_{\mathrm{W}}=\text { winding resistance }
\end{aligned}
$$

The inductance L is given by (Ref. 2);

$\mathrm{L}=\left(\mu_{\mathrm{r}} 0.4 \pi \mathrm{N}^{2} \mathrm{~A}\right) /\left(l * 10^{8}\right)$ henries

Where: $\quad \mathrm{A}=$ cross sectional area of the core $\left(\mathrm{cm}^{2}\right)$

$l=$ mean magnetic path length $(\mathrm{cm})$

$\mu_{\mathrm{r}}=$ relative permeability of material 
5. Scaled Design Changes and Testing Results

An Arnold Magnetics Supermalloy core wound with 0.002 inch tape was used as a testing model. The core had a 0.5 inch square cross section, and when measured with its aluminum housing, an ID of 6.875 inches and an OD of 8.125 inches (core measurements were 7.0" ID and 8.0" OD). This core was wound with 100 turns of \#28 kynar insulated wire (0.013"Diam. wire, 0.022"Diam. insulation). The windings were bound with a $1 / 4$ inch ungrounded strap that was used as a low inductance plane to connect $1 \mathrm{~K}$ ohm "damping" resistors separated by 5 turns, thus providing a total of 20 resistors. When loaded with about $1.5 \mathrm{ohms}$ ( two $3.0 \mathrm{ohm}$ resistors in parallel) this transformer exhibited considerable peaking at about $18 \mathrm{Mhz}$ and had a low frequency cut-off of about $2 \mathrm{~Hz}$ (see fig.1).

An effort was made to improve the transient response by reducing the ringing due to peaking, maintaining the upper cut-off frequency and extending the low frequency response. To accomplish this, a new transformer was wound with 100 turns, but was separated from the core case by about $1 / 32$ inch with a cardboard spacer. This was done to reduce coil capacitance to the case, which contributes to the high frequency and transmission line affects. A special testing facility was constructed to provide a single turn primary winding that would pass current through the center of the transformer core, improving magnetic symmetry, and providing shielding to minimize capacitive coupling from the primary and stray external magnetic field pickup.

The reduced capacitance transformer also required "damping" resistors. These resistors were not wired to a ground strap as before, instead, they bridged the 5 turns directly. This was done to avoid additional coil capacitance. It was found that the transient response was greatly affected by the resistors connected to the end 5 turns, and the value of the load resistance. A response comparison is shown in figures $2 \& 3$.

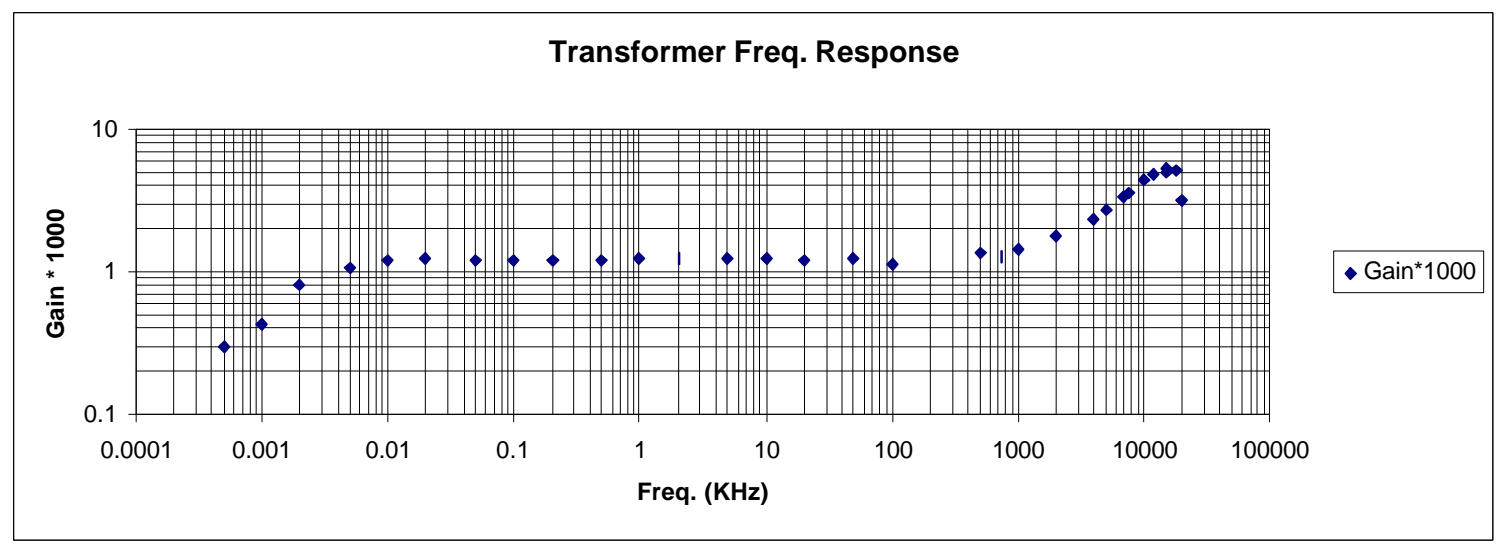

Figure 1 -Response of original BCM with 100 turn secondary, twenty $1 \mathrm{~K}$ Ohm damping resistors connected to a floating ground strap separated every 5 turns, and a $1.5 \mathrm{Ohm}$ load, to a $4.65 \mathrm{~V}$ peak sinusoid into a three turn primary terminated with $47 \mathrm{Ohms}$. 


\section{LOW CAPACITANCE XFMR - RL=1.5 Ohms with No Resistors, $1 \mathrm{~K}$ across ea. 5 turns, \& 2 ea. 120 || 1K, \& 47|| $1 \mathrm{~K}$ on first \& last 5 turns as well as $1 \mathrm{Ks}$ as before}

$-\cdots 57$ Ohms ……1K Ohms --*-45 Ohms — No Resistors

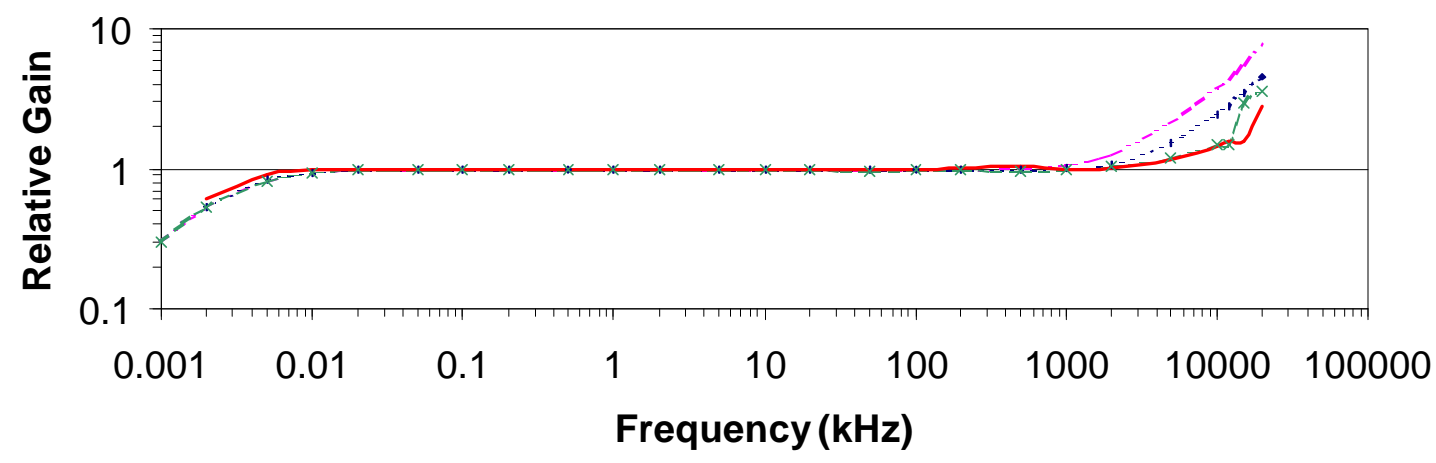

Figure 2 - Response of a reduced coil capacitance transformer to various terminating "damping" resistors. The remainder of the transformer had $1 \mathrm{~K} \mathrm{Ohm} \mathrm{resistors} \mathrm{bridged}$ across each 5 turns. The secondary was terminated with two $3.0 \mathrm{Ohm}$ resistors in parallel.

The importance of properly selecting the load resistance is shown in figure 3. An upper cut-off frequency of about $20 \mathrm{MHz}$ was achieved with a lower cut-off frequency of about $5 \mathrm{~Hz}$. The resistance determining transient behavior comprises both the physical load resistor and the wire resistance. The \#28 wire provided about $1.2 \mathrm{ohms}$ of secondary resistance. Transient response behavior is shown in the oscilloscope traces of figures $4,5, \& 6$. Of interest in observing these oscillograms is the fact that the input waveshape presented by the LeCroy 420A arbitrary waveform generator provided sufficiently high frequency components to stimulate some ringing in the response (figure 6). The Analogic 2030 pulse generator had a smooth rising edge, which was sufficiently band limited to produce a smooth output signal with minimal ringing (figure 5). The bunch is not expected to be sharp edged except for the first turn. 


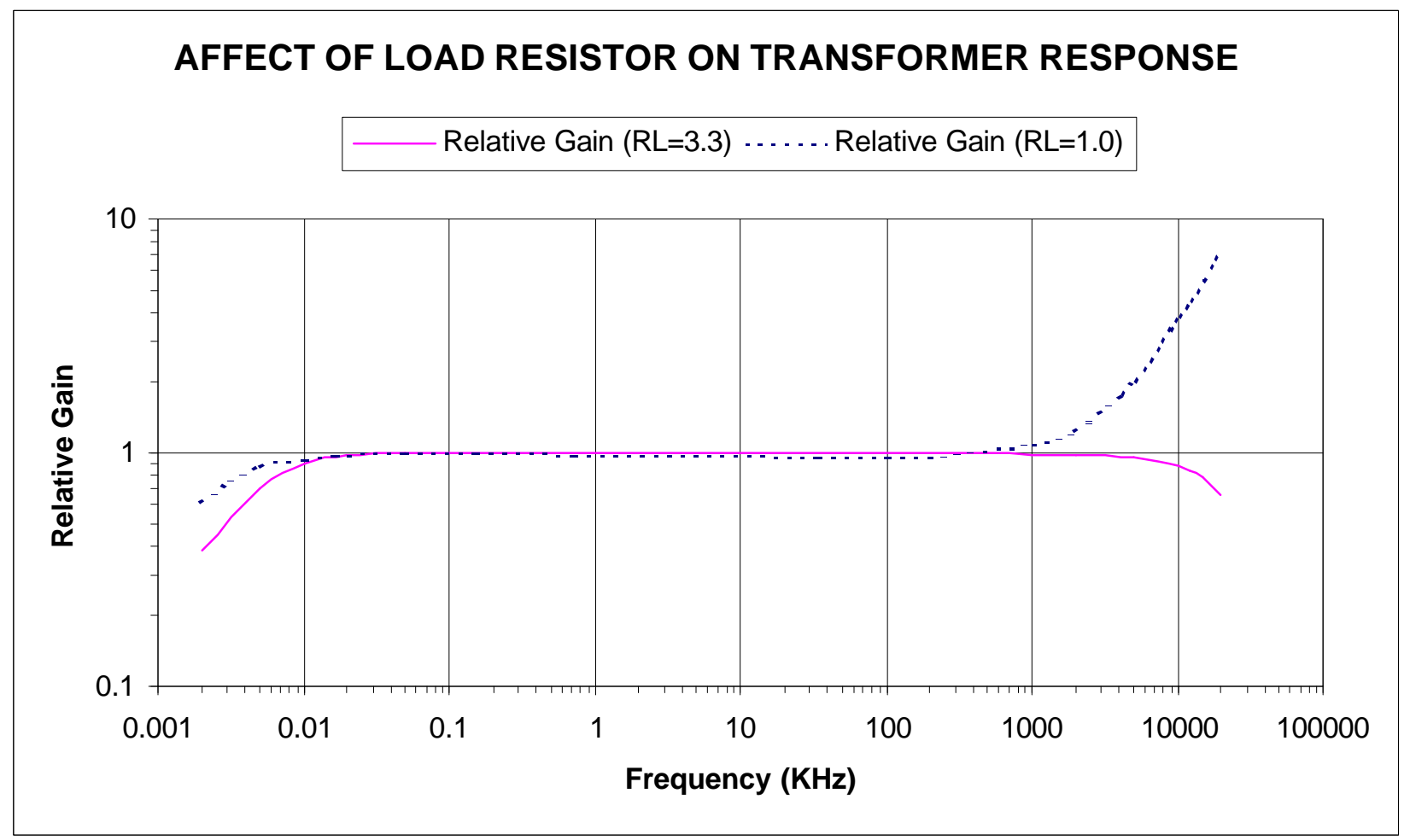

Figure 3 - Response of a reduced coil capacitance transformer with $1 \mathrm{~K} \mathrm{Ohm} \mathrm{"damping"}$ resistors bridged across each 5 turns and $120 \mathrm{Ohms}$ at ends, to different load resistors.

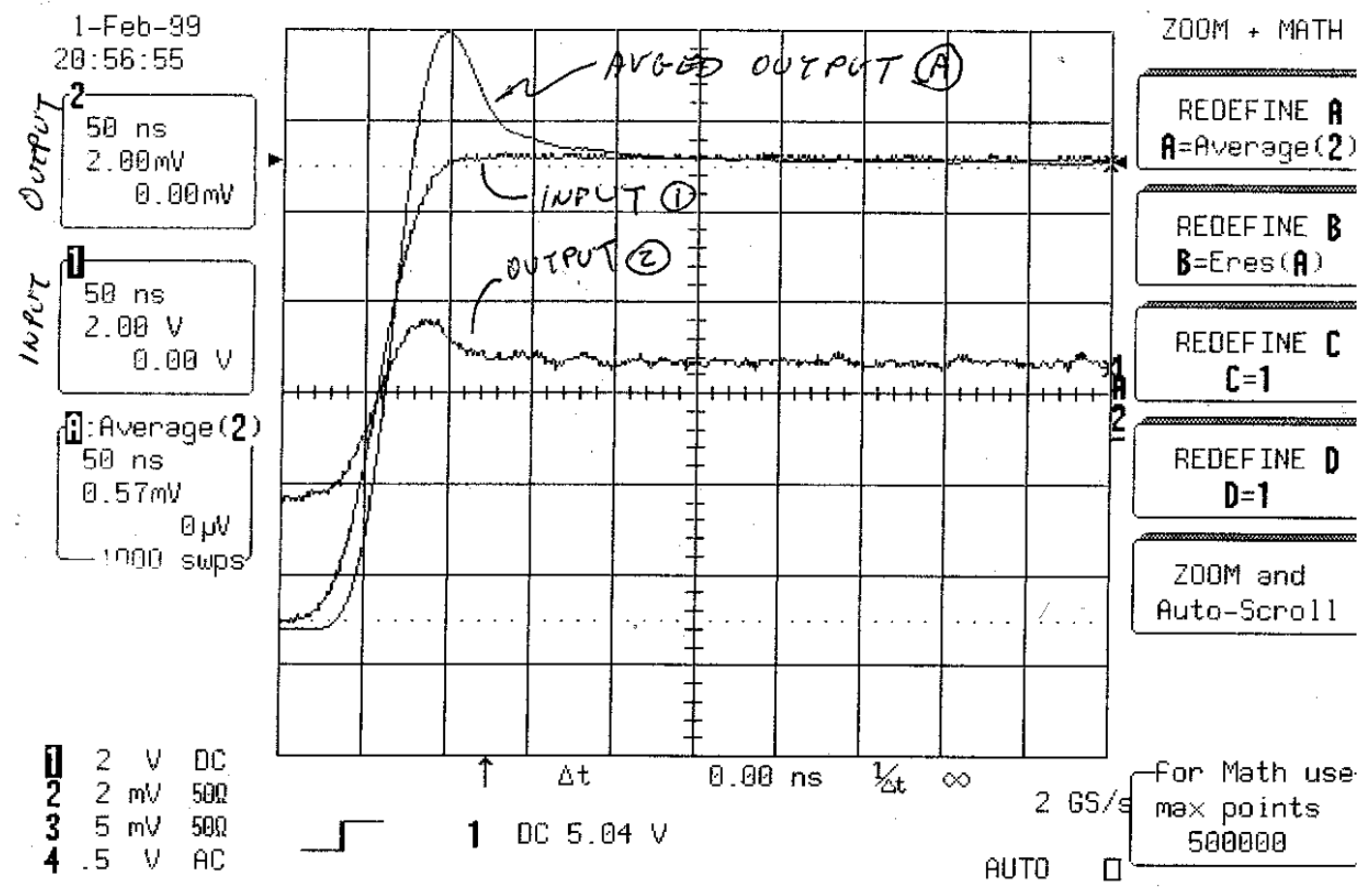

Figure 4 - Original transformer transient response. 


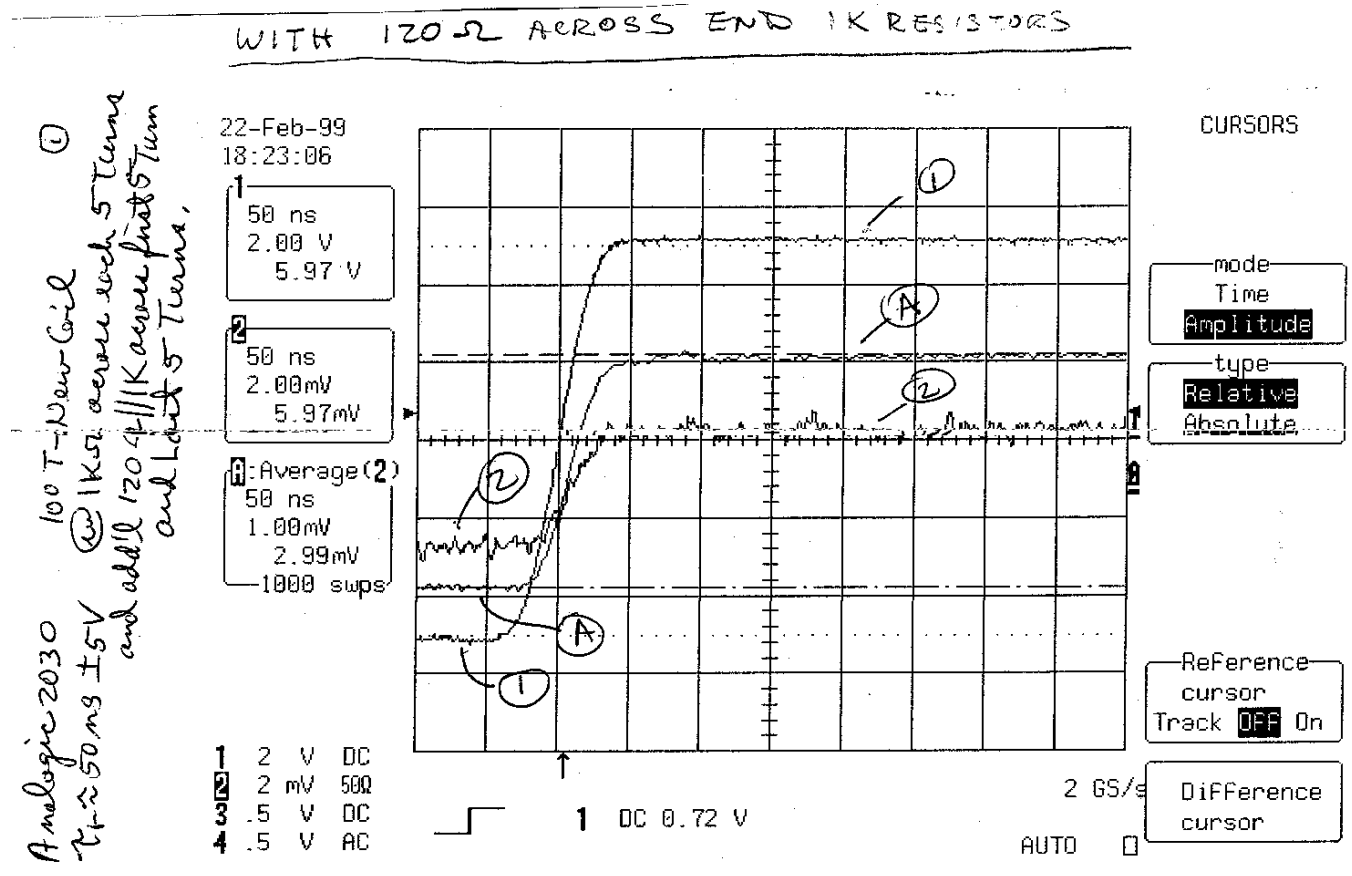

Figure 5 - Reduced capacitance transformer response with $120 \mathrm{Ohm}$ end section damping resistors and 1.5 Ohm load. Stimulus was an Analogic 2030 pulse generator.

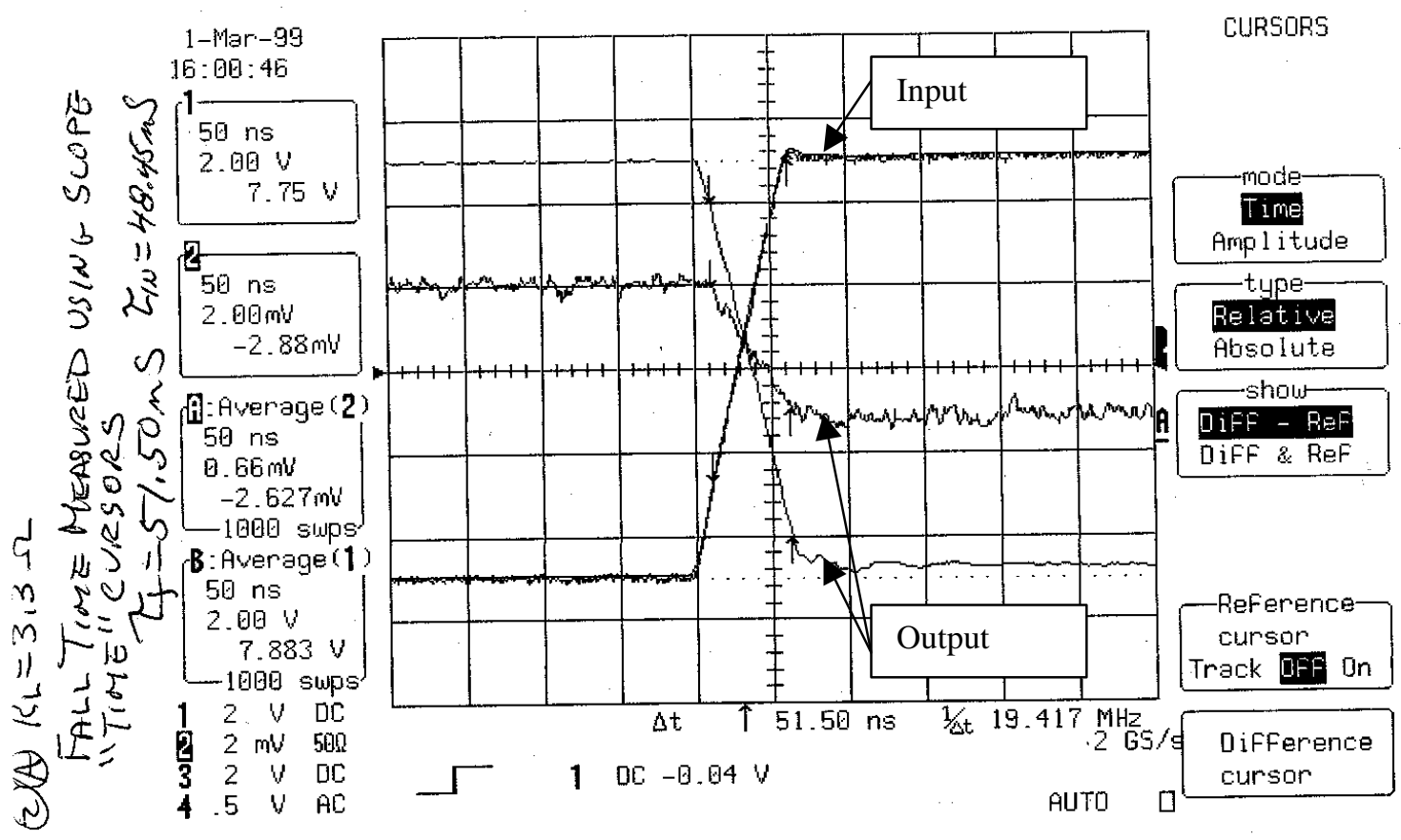

Figure 6 - Reduced capacitance transformer of figure 5 transient response for $R_{L}=3.3$ Ohms. Stimulus was LeCroy 420 A arbitrary waveform generator set to a 50ns rise time. 
Scaled Transformer:

To scale the low frequency response, an increased inductance of about $5 / 0.16=31.25$ is required assuming a constant resistance, and no regard to transient affects. As described in section 4, this can be accomplished by an increased number of turns or core size. A larger core or increased turns will increase leakage inductance, winding resistance and stray capacitance due to more wire used in the secondary. This will reduce the natural resonance, slowing the rise time. The use of larger wire can compensate somewhat for increased wire lengths, but it will further increase stray capacitance. Winding methods can be utilized that will lift the winding away from the core with a minimal of dielectric material, leaving an air space that will reduce the permittivity by a factor of two to three, thereby reducing stray capacitance.

Two cores were ordered to fit the SNS beam pipe diameter and increase inductance due to increased core size. One has a 9.5 inch ID and 14 inch OD, with a core cross section of 2.25 inches by 3.0 inches, the other has a 9.5 inch ID and an 11.5 inch OD with a core cross section of 1 inch square. By "tuning" the transformer winding method, size, damping and load resistance, it is felt that one will come near to meeting the design goals. It is expected some compromise may still be required.

Table 3 shows some estimates of the parameters that would relate to the transformer design for comparative purposes and approximate scaling. It should be noted that it was assumed (Ref. 3) that the leakage inductance would be proportional to $\mathrm{N}^{2} \mathrm{~h} \ln (\mathrm{OD} / \mathrm{ID})$

(where $\mathrm{h}$ is the height of the core, OD is outside diameter, ID is inside diameter).

Table 3 - Scaling Trends for Three Supermalloy Cores

\begin{tabular}{|c|c|c|c|}
\hline & Core 0 & Core 1 & Core 2 \\
\hline ID (inches) & 7.0 & 9.5 & 9.5 \\
\hline OD (inches) & 8.0 & 14.0 & 11.5 \\
\hline Height h (inches) & 0.5 & 3.0 & 1.0 \\
\hline $\mathrm{A} / l(\mathrm{~cm})$ & 0.02695 & 0.46446 & 0.077 \\
\hline $\begin{array}{c}\text { Wire Length (inch) } \\
\text { per 100 turns }\end{array}$ & 200 & 1050 & 400 \\
\hline $\begin{array}{c}\mathrm{L}_{\mathrm{e}} \alpha \mathrm{N}^{2} \mathrm{~h} \ln (\mathrm{OD} / \mathrm{ID}) \\
\left(\mathrm{inch} / \mathrm{turn}^{2}\right)\end{array}$ & 0.06677 & 1.1633 & 0.19105 \\
\hline$(\mathrm{A} / l) /(\mathrm{A} / l)_{0}$ & 1 & 17.23 & 2.857 \\
\hline $\mathrm{L}_{\mathrm{e}} / \mathrm{L}_{\mathrm{e} 0}(\mathrm{~N}=100)$ & 1 & 17.4 & 2.9 \\
\hline $\mathrm{C} / \mathrm{C}_{0}($ for 100 turns $)$ & 1 & 5.25 & 2 \\
\hline $\begin{array}{c}\mathrm{L}(\text { Henries }) \text { for } 100 \\
\text { turns }(\mu=40000)\end{array}$ & 0.115 & 1.98 & .329 \\
\hline
\end{tabular}

The larger core (core 1) could provide a 17.2:1 increase in inductance (based upon A/l alone) which will yield a lower corner frequency of about $0.3 \mathrm{~Hz}$ (slightly short of the 0.16 required). Leakage inductance and stray capacitance will increase, reducing the high frequency response. 
Transient response requirements will affect the required load resistance. This will modify the droop somewhat more. It is not clear how well the windings can be "tuned".

The smaller core (core 2) will not deliver the inductance without increasing turns. A balance between wire size, turns, and load resistance must be found empirically to achieve a compromised goal. Once again, the required load resistance to achieve an appropriate transient response is not known, and this may effect the rise time, and droop. The transformers must be "tuned" in an attempt to achieve a good transient response, droop, and rise time. It is believed that one can come to within approximately a factor of two of these goals.

\section{6- System Block Diagram and explanation}

Different electronics are required to process the signals developed by the FCT and BCM. The FCT requires an amplifierwith a frequency response extending to about $350 \mathrm{MHz}$. Since droop is specified as $0.1 \% / \mu \mathrm{s}$, a lower cut-off of $159 \mathrm{~Hz}$ will suffice. An amplifier capable of accepting the signals expected in the HEBT (56mA) as well as a buffer suitable for transferring data to a data acquisition system will be required. To acquire HEBT BCM data, lower bandwidth electronics will suffice, along with capabilities to integrate the beam current to obtain charge information for each mini-bunch. High speed reset is necessary which will require an ability to switch between integrators to allow sufficient settling time. A fixed gain amplifier will be sufficient. A track/hold will acquire the signal in the gap between mini-bunches for acquisition by an $\mathrm{ADC}$ at the ring revolution frequency of about $1.18 \mathrm{MHz}$.

The RTBT has only FCTs and will require both a high gain for low power studies, and a low gain for full operational power levels. The signals will also be integrated to provide total charge delivered per ring cycle. In addition the electronics will provide wide bandwidth, and high-speed digitization to acquire pulse characteristics during the 550ns beam.

The RING electronics must be far more sophisticated. It must provide adequate gain for observing the lower level injected pulses for early turns and initial investigations at low power, as well as reduced gain and dynamic range suitable to analyze the accumulated beam after more than 1000 turns. Both the FCT and BCM must have a large dynamic range. All of the elements of the FCT are included in the BCM electronics and a block diagram is presented in figure 7.

The current transformer will be interfaced with a differential amplifier. This feeds a set of variable gain amplifier stages. Depicted is the AD602, a $35 \mathrm{MHz}$ low noise dual $30 \mathrm{~dB}$ amplifier with a voltage controlled $40 \mathrm{~dB}$ input attenuator, linear in $\mathrm{dB}$. The amplifier will not respond to a gain change within the 300ns gap time, so a second amplifier is included with switches that permit looking at one or the other. In this way, it is intended to set an amplifier gain some time before it is needed, and then switch as necessary. Only a few gain settings will be necessary, however, the programmability of the gain can be made flexible with digital registers and DACs, or it can be established with fixed resistor settings and analog switches for more simplicity. The analog output will be buffered for the data acquisition system. If the $0.1 \%$ droop cannot be achieved a baseline restorer circuit may be required. For each turn, the current will be integrated by a dual integration (Ping-Pong) technique to permit one integrator to be resetting while the 
other is integrating. The integrated charge signal will be buffered for data acquisition. Although relays are shown in the block diagram they are pictured only for functionality. An appropriate switch will be chosen during the design process. Due to amplifier offset errors and high gain, an automatic adjustment is included to zero the output during the $15.6 \mathrm{~ms}$ of no beam. This circuitry must be switched on and balance the output within the $15.6 \mathrm{~ms}$ and hold this correction for the duration of the $1 \mathrm{~ms}$ pulse. This is required to avoid amplifier saturation due to offset when operating at high gains. 


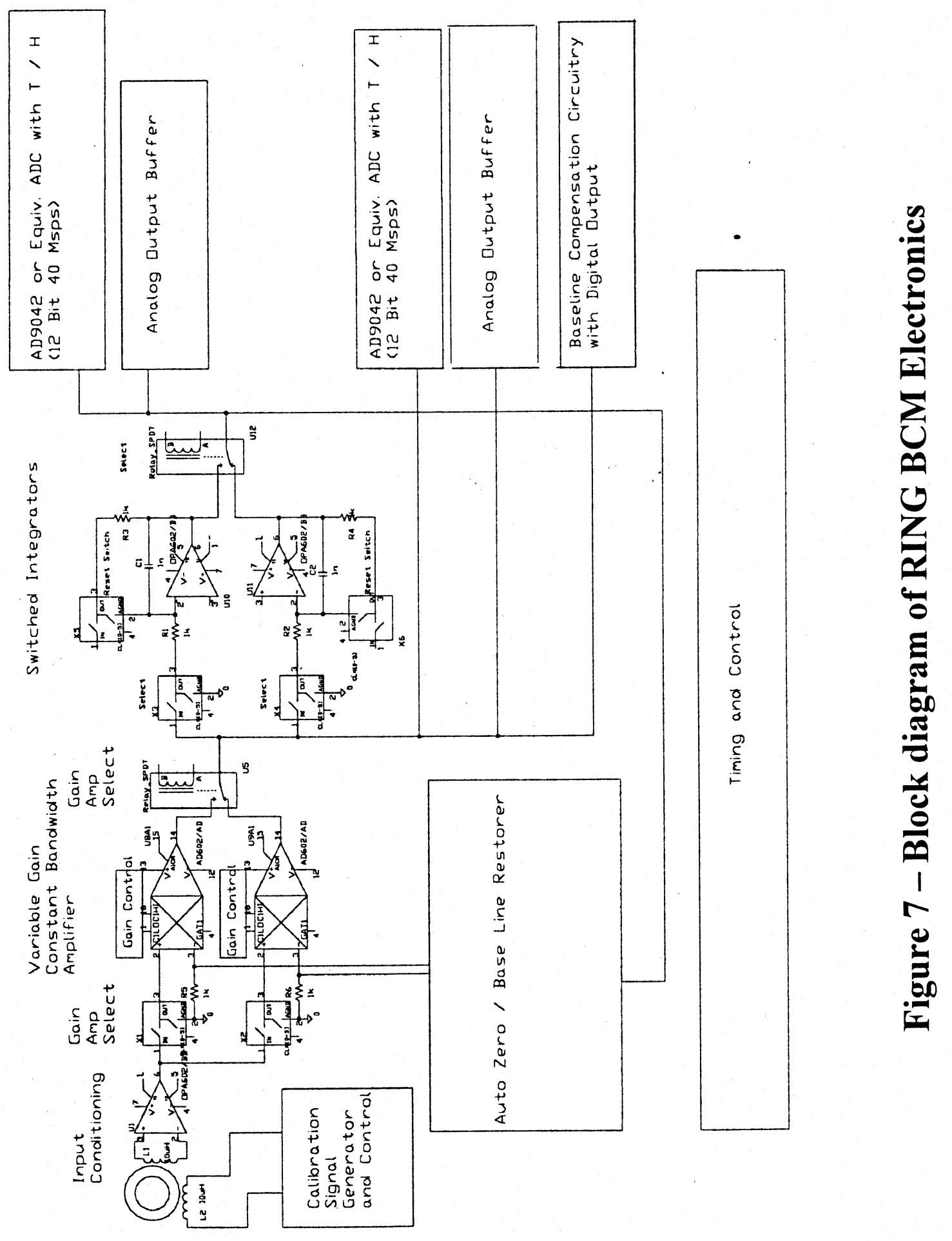

Page 12 


\section{Conclusions}

The Beam Current monitors required by the SNS RING can be provided by two different current transformers, a FCT and a BCM of special design. The FCT is a purchased item and should offer little difficulty in design. The BCM will require significant low frequency response to develop minimal droop during the one millisecond macrostructure pulse. It also requires a reasonable rise time to respond to the mini-structure, 546ns pulse and 295ns gap. By careful "tuning" of the coil winding, a low capacitance coil can be wound to achieve the desired 50ns to $70 \mathrm{~ns}$ rise time with nearly a 1 second droop time constant. Transient response is difficult to predict, and was found to be very dependent upon the load resistance (winding plus load). This resistance affects the L/R time-constant as well and could compromise the droop performance. A trade-off between rise time, droop and transient response may be required. To achieve the desired results two cores have been ordered to allow experimentation into different transformer characteristics. A BIG monitor is far more difficult to achieve due to the extreme transient performance requirements. This requires additional research and development.

\section{References:}

1- "Wave generation and Shaping"; Leonard Strauss Mc Graw-Hill 1960, pg.397

2- "Catalog"; National-Arnold Magnetics 17030 Muskrat Ave., Adelanto, CA 92301

3- "Inductance Calculations - Working Formulas and Tables"; Frederick W. Grover, Dover Publications 1946. 
Appendix:

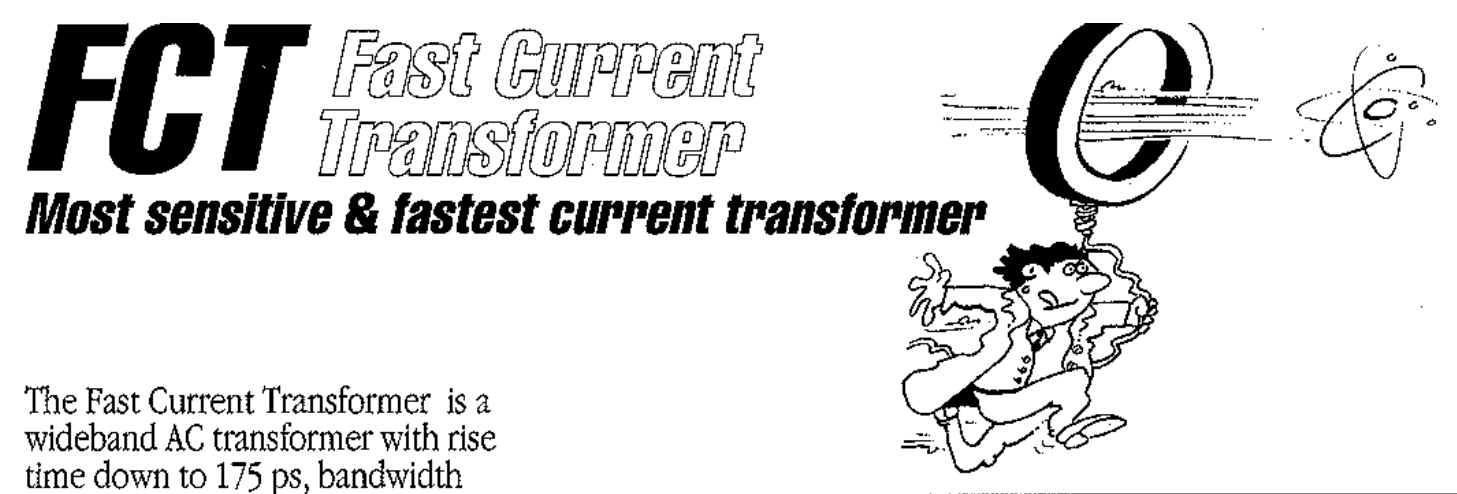

up to $2 \mathrm{GHz}$

\section{To measure}

\section{Pulsed beams in particle} accelerators

\section{Partial discharge pulses from corona wires, in insulation defects}

\section{Current rise in semiconductor gates, triggers}

\section{Surge current waveforms in EMI/EMC analysis}

\section{Capacitive discharge pulses}

Passive models do not include any electronics. Sensitivity up to 5 V/A

Active models include wideband amplifiers. Sensitivity up to 500 $\mathrm{mV} / \mathrm{mA}$

Apertures from $16 \mathrm{~mm}$ up to 178 mm. Larget on request

\section{New technology}

Used world-wide on all high-energy particle accelerator to observe very short beam pulses. Exceptional bandwidth and sensitivity are achieved by using amorphous cobalt-based alloy cores specially annealed in a magnetic field to obtain very high permeability and low loss at frequencies to $2 \mathrm{GHz}$.

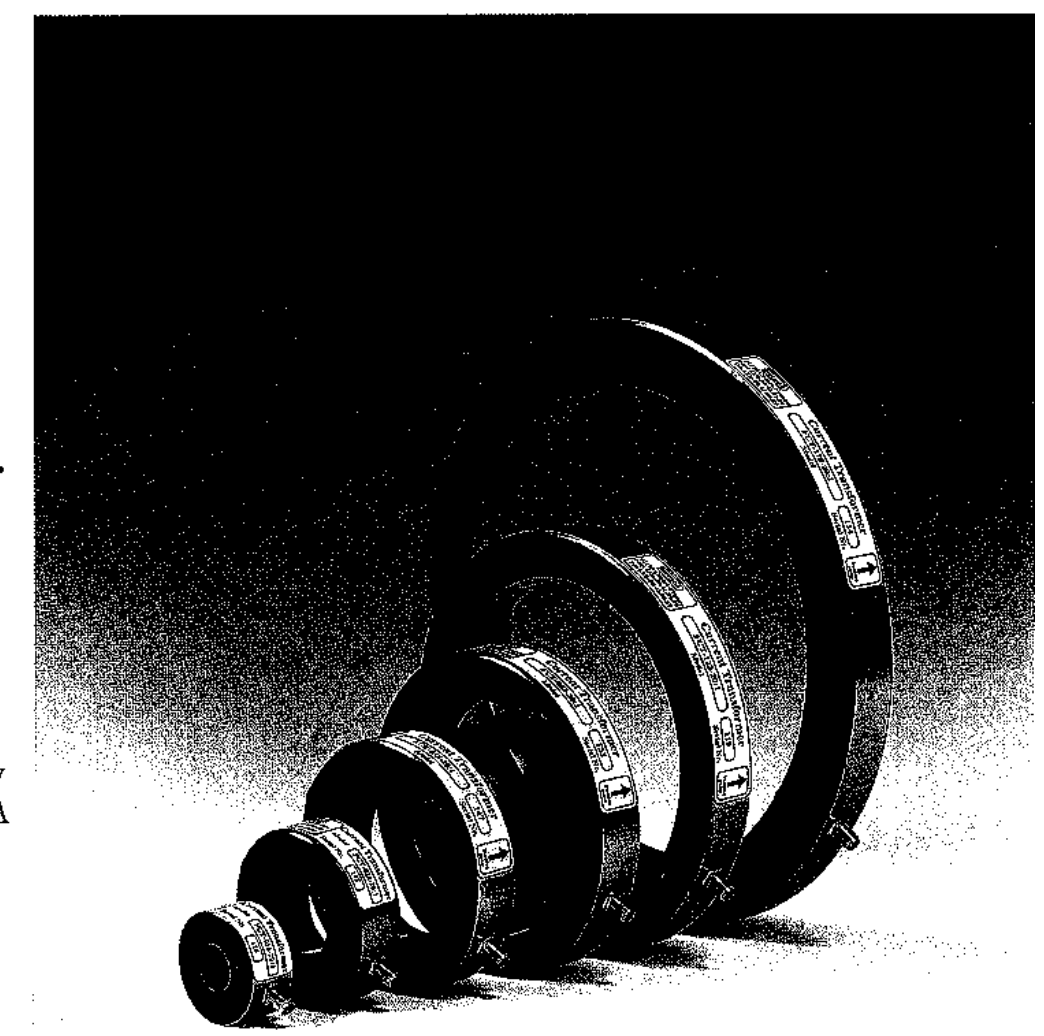

Photo Bugey

Highest sensitivity models

Passive transformers with highest sensitivity: $5 \mathrm{~V} / \mathrm{A}$ are made with aperture up to $122 \mathrm{~mm}$ and bandwidth up to 1.3 GHz@-3dB. Higher sensitivity, up to 500 $\mathrm{mV} / \mathrm{mA}$ is obtained with active models featuring a wideband amplifier. Amplifiers are powered through the coaxial cable.

\section{Fastest models}

Models with sensitivity $1.25 \mathrm{~V} / \mathrm{A}$ are fastest: $2 \mathrm{GHz} @ 3 \mathrm{~dB}, 175$ ps risetime. Aperture up to $178 \mathrm{~mm}$, even larger on request.

\section{Largest aperture}

Apertures up to $500 \mathrm{~mm}$ have been made on request. Bandwidth depends on sensitivity required. 


\begin{tabular}{|c|c|c|c|c|c|c|}
\hline Primary current to output ratio & 1001 & $50: 1$ & 201 & 10:1 & 051 & \\
\hline Sensitivity (nominal) & 025 & 0.5 & 125 & 2.5 & 9.0 & $\mathrm{~V} / \mathrm{A}$ \\
\hline Rise time (typ.) & 600 & 300 & 200 & 300 & 500 & \\
\hline Linearity error (above $100 \mathrm{kHz}$ ) & $\mathbf{r 1}$ & $<1$ & $<1$ & $<1$ & +1 & \\
\hline Droop & $<1$ & $<3$ & $<6$ & $<10$ & $<20$ & $\% / \mu s$ \\
\hline Eddy current loss & $<15$ & $<15$ & $<15$ & $<15$ & $<15$ & $\%$ \\
\hline Position sensitivity (on axis) & $<0,2$ & $<0.2$ & $<02$ & $<0.2$ & $<020$ & $\% / \mathrm{mm}$ \\
\hline L/R time constant (min.) & 100 & 35 & 17 & 10 & 5 & $\mu s$ \\
\hline Max. charge/pulse (pulses < lns) & 2 & 1 & 0.4 & 0.2 & 01 & $\mu \mathrm{C}$ \\
\hline Max. peak current (pulses $>1$ ns) & 2000 & 1000 & 460 & 200 & 100 & A \\
\hline Max. the current $(f>10 \mathrm{kHz})$ & 28 & 14 & 5.6 & 2.8 & 1.4 & A \\
\hline
\end{tabular}

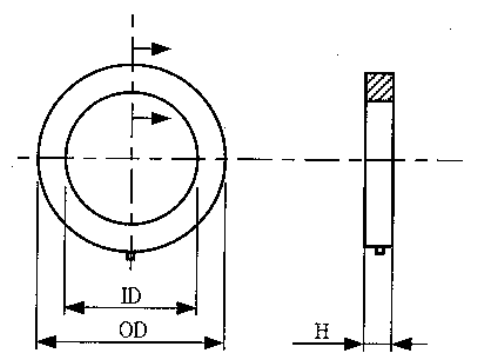

\section{Ordering Codes}<smiles>C[13CH](C)C</smiles>

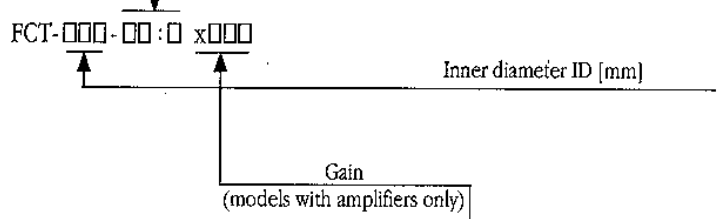

Active amplification

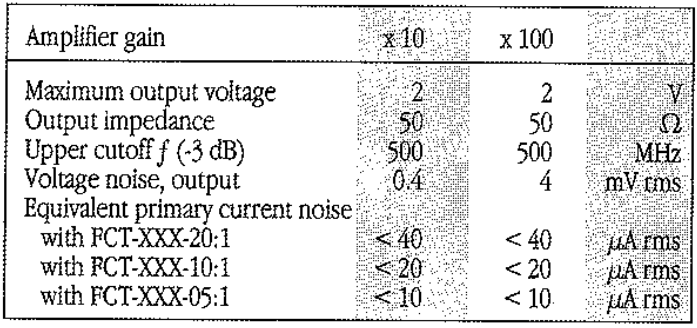

Schematic diagram

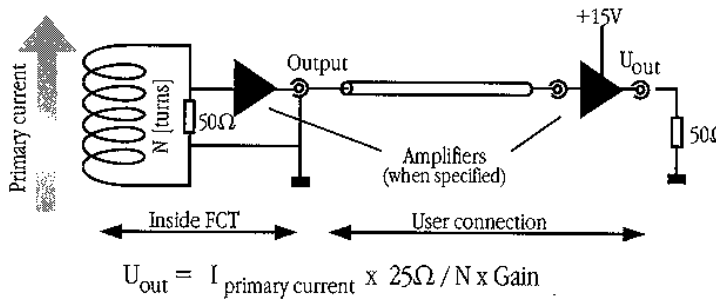

Options

Rad-hard sensor: $6 \times 10^{7}$ Gy max., append "-H" to ordering code BNC connector instead of SMA, append "-B" to ordering code $\mathrm{N}$ connector instead of SMA, append " $-\mathrm{N}$ " to ordering code

\begin{tabular}{|lrrrr|}
\hline $\begin{array}{l}\text { Ordering } \\
\text { codes }\end{array}$ & $(\mathrm{min})$ & $\begin{array}{c}\text { OD } \\
(\max )\end{array}$ & $\begin{array}{c}\text { H } \\
(\mathrm{m} 2 \mathrm{x})\end{array}$ & $\begin{array}{l}\text { Mass } \\
(\mathrm{g})\end{array}$ \\
\hline FCT-016-XX:X & 16 & 42 & $22 *$ & 60 \\
FCT-028-XX:X & 28 & 64 & $22 *$ & 115 \\
FCT-055-XX:X & 55 & 91 & $22 \%$ & 175 \\
FCT-082-XX:X & 82 & 118 & $22 \%$ & 250 \\
FCT-122-XX:X & 22 & 156 & $22 \%$ & 320 \\
PCT-178-XX:X & 178 & 226 & $22 \%$ & 700 \\
\hline
\end{tabular}

*Models $10: 1$ and $05: 1$ may be wider All dimensions in $\mathrm{mm}$ Environment

Temperature: $80^{\circ} \mathrm{C}$ max. (storage and operating) Ionizing radiation: $10^{3}$ Gy max.

\section{Connectors}

SMA female $50 \Omega$ (BNC connector on option)

\section{Distributors}

U.S.A. : GMW Associates

P.O. Box 2578

Redwood City, CA 94064, U.S.A.

Fax:(650) 802-8298 Tel.: (650) 802-8292

Email: sales@gmw.com

Japan : REPIC Corporation

28-3, Kita Otsuka 1-Chome

Toshima-ku, Tokyo 170, Japan

Fax: 03-3918-5712 Tel.: 03-3918-5326

$50 \Omega$ Manufacturer

BERGOZ Instrumentation

Espace Allondon Ouest, 156 rue du Mont Rond 01630 Saint Genis Pouilly, France

Fax: $+33-450.426 .643$ Tel.: $+33-450.426 .642$ Email: sales@bergoz.com

The Fast Current Transformer was developed in collaboration with Klaus Unser of CERN, the Particle Accelerator Laboratory in Geneva, Switzerland

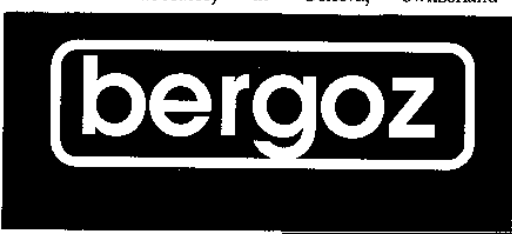

